\title{
Research on the Application of Internet of Things Technology in Intelligent Home
}

\author{
Wencai $Y \mathrm{e}^{1, \mathrm{a}}$ \\ ${ }^{1}$ Jimei University, School of Information Engineering, Fujian, Xiamen, China, 361012 \\ ${ }^{a}$ email,
}

Keywords: Internet of Things Technology: Smart Home: Application

\begin{abstract}
In recent years, with the rapid development of Internet of Things technology, the application of Internet of Things technology in intelligent home has also been rapid development, therefore, this article mainly for the Internet of things in the application of intelligent home in the main management system, The architecture of the Internet, the application trend of the Internet of Things technology in the future intelligent home, and so on. The application of the Internet of Things technology in the intelligent home has been studied and analyzed in detail. It is hoped that through this article, intelligent home applications to provide a certain reference.
\end{abstract}

\section{Introduction}

The application of Internet of Things technology in smart home is a new technology that makes home life more intelligent and convenient by acquiring information data. At the same time the Internet of Things technology as an intelligent network system, in the smart home to maintain a relatively adaptive, and has a certain cognitive ability. Since the late nineties of the twentieth century, the United States after the Internet of Things technology, through the Internet of Things technology in the application of intelligent home life, can be said that the human way of life had a significant impact, Internet of Things technology is constantly changing the way people interact with nature. Although the application of Internet of Things technology in the smart home in China started late, but with the rapid development of Chinese information science and technology, nowadays, Internet of Things technology in our smart home has been a very wide range of applications, Home life application of Internet of things technology, not only to a large extent effectively reduce the consumption of home energy, to avoid the safety of home electronic equipment and other shortcomings, not as much as in the past, the need for indoor staff for twenty-four hours Care and waiting. Through the application of Internet technology in intelligent home life, it is extremely effective in reducing the waste of human resources, saving people's living time in modern society, realizing the purpose of network technology covering the whole family life, and making our modern life convenient and convenient.

\section{The Main Management System of the Internet of Things in the Smart Home Application}

With the continuous development of information science and technology in our country, the application of Internet of Things technology in intelligent home is more and more extensive, from various family energy management subsystem, family water management system, home intelligent security management subsystem to indoor ventilation management sub systems, etc., things are gradually changing the way people's daily life.

Family Energy Management Subsystem. In the era of modern smart home popular, through the intelligent home among the family energy management subsystem, can be a very good realization of the family indoor energy rationalization management. For example, in the past, most of our traditional families, mainly through the summer use of air conditioning and refrigeration equipment, the use of heating facilities in winter to achieve the family's indoor temperature control. But when people need to leave the house for some time, in order to be able to return to the house immediately in the warm and cool summer state, you need to come out in front of the air conditioning or heating in a state of continuous open, but this way to a large extent Increasing the 
cost of household energy consumption. But the smart home in the family energy management subsystem is able to remote and other technical means, when people after get off work through a smart phone or computer, the indoor energy subsystem management and control to ensure that people will enter the house before half an hour or an hour ago to open the air conditioning or heating. At the same time, intelligent home through the use of Internet of things technology, but also to automatically adjust the body's temperature comfort requirements, in the realization of Dongnuanxialiang under the premise of the indoor long time at $20 \sim 22{ }^{\circ} \mathrm{C}$ human body feel the most comfortable between the temperature, And can be extremely effective in reducing household energy consumption [1].

Household Water Management Subsystem. The household water management subsystem in the intelligent home can be automatically adjusted by circulating water and ecological water saving, and the waste water can be recovered, filtered and processed, so that part of the living wastewater can be used for flushing, The other part is used to carry out drip irrigation or micro-irrigation irrigation in the indoor way, through the Internet of Things technology used in the intelligent home life which can effectively achieve the source of throttle to achieve the family indoor water and recycling water use to maximize the effect.

Indoor Ventilation Management Subsystem. Intelligent home ventilation management subsystem which can make full use of wind resources to the indoor family which, in order to avoid the cost of expensive ventilation equipment, intelligent home through the use of Internet of Things technology, according to the indoor air turbidity, automatic hot air up and discharge, Cold air sink into the indoor automatic adjustment function. The automatic recirculation type ventilation system can follow the wind direction, at the same time, reduce the ventilation may bring the heat loss, but in the role of natural hot pressure to form a pure natural ventilation. Therefore, the smart home indoor ventilation management subsystem, not only to let the people in the room always feel the fresh air and comfort, there will be no slight oppressive situation. At the same time, intelligent home among the family ventilation management subsystem can adapt to different changes in the external wind and change, people seem to be among the nature, and then the formation of the feeling of harmony between man and nature.

Family Intelligent Security Management Subsystem. Internet technology through the use of intelligent home life, can be a large extent effective on the indoor safety to remind, through the family intelligent security management system, once the family indoor gas leak or indoor fire, etc., the occurrence of things Networking technology through the intelligent home in the indoor automatic fire fighting and window control system, can be reduced to a large extent or even put an end to the occurrence of family accidents and accidents. And if there are windows and doors were destroyed, the robbers into the room and so that the emergence of the situation, the family intelligent security management subsystem will be the first time automatically contact the relevant public security departments, while voice reminders living in the outdoor staff, so as to ensure Indoor home security.

\section{System Architecture of the Internet of Things in the Smart Home}

Internet technology has actually started the earliest in the last century, now, with the global information science and computer science sustained and rapid development, Internet of Things technology has become a widely used and put into use technology. Although nowadays, a variety of network technology after another, but the status of Internet of Things technology is still unable to shake, especially now, Internet of Things technology has been cut into the real life of the various entities and physical networks to go, Internet of Things technology has become a major development in the future of the world's major productive forces, but also the future of scientific development of the first department, through the Internet of Things technology in the smart home research, can help our lives become more convenient and efficient. The Internet of things technology, including the perception layer, network layer and application layer three technical modules: 
The Construction of the Perception Layer. Sensing layer as the Internet of Things technology architecture in the most basic, the bottom of the means. Sensing layer in the use of intelligent home, mainly through the GPS, two-dimensional code, infrared, camera, sensor and a series of methods and methods to achieve intelligent home equipment in the perception of the function, such as room temperature perception, humidity perception, Wireless gas perception, etc., so as to smart home among the application of Internet of Things to do the basic operation.

Network Layer Construction. The network layer is the most important because the network layer can provide an effective connection for the exchange of information data for each node in the Internet of Things. At the same time, the network layer can also be the network equipment for the Internet of Things data exchange between sensing devices, data exchange between sensing devices, data exchange between network devices and sensing devices, and network equipment configuration. In short, the network layer is to achieve a complete set of sound and interactive systems. For example, nowadays, through the use of Internet technology on wireless air quality cleaners, the real-time air quality data can be transmitted to the air quality purifier inspection platform through the network layer in the Internet of Things, The network layer can ensure that the data is absolutely accurate, so that the platform can automatically through the built-in software system for indoor air quality analysis, which automatically achieve the indoor air quality adjustment and purification functions [2].

Application Layer Construction. The application layer in the Internet of Things technology is mainly to express and express the data of the sensing layer and the network layer. The application layer in the Internet of Things technology is composed of a number of specific application service elements and one or more public application service elements, and each specific application service element can provide specific application services.

\section{The Application Trends of Internet of Things in the Future Smart Home}

As a comprehensive technical means of wireless technology, such as wireless communication technology, sensor technology, computer information network technology and so on, through the detection of the detection side, monitoring and information access, in order to achieve the virtual world and physical world of communication and interaction. At present, more and more intelligent home manufacturers are committed to the Internet of things in the application of intelligent home, and the future of things in the smart home applications will also be more intelligent, user-friendly, automated and electronic wait.

Energy Saving and Environmental Protection Trends. With the lack of energy and environmental pollution has become a global topic, how to use the limited energy to achieve greater economic benefits, has become a modern smart home industry is facing enormous challenges. Therefore, it is necessary in the smart home in the use of more and more advanced means of Internet of things, to ensure that people living comfortably living and living environment under the premise of better realization of smart home energy saving, natural environmental protection, economic, practical and many other features.

Digitization Trend. With the rapid development of science and technology in China, the digitalization of intelligent home is changing with the characteristics of interactivity and immediacy, massivity and sharing, multimedia and hypertext, individualization and communityization. In the past, all aspects of traditional home life, making modern smart home life began to become more human and lively. At the same time, the application of Internet of Things technology in the smart home, will also make the smart home industry more and more digital, this feature is now the first to develop the smart digital TV industry, intelligent digital TV since the advent of the traditional TV The market has been changed through a variety of naked eye 3D, somatosensory games, curved three-dimensional cinema, VR, etc. are subtle into the people's lives. And other types of smart home appliances, the development of its digital function is only a matter of time, the future of things networking technology will be able to more fully help more intelligent home products to achieve digital technology leap [3].

Automated Trends. Nowadays, the world of the world's Internet has become the mainstream of 
people's production and life, Internet of things in the intelligent home life in the remote control and access to information such as automation, will also be the latest features of smart home. For example, in many developed countries in Europe and the United States, through the smart home in the wireless sweeping machine and the use of Internet objects in the technology, has been achieved on the ground floor space and sweeping machines, mopping machine traffic and stay in full Combined with the help of sweeping machines and tractors of the sensor device, the indoor home equipment to identify the specific location of the method, the signal through the Internet of things to the corresponding network platform. Sweepers and mopping machines inside the control system will be synchronized to receive the wireless network from the platform instructions to remind the sweeping machine and drag the machine to switch the operating speed or trajectory, so as to avoid the indoor sofa appliances. And when someone or a pet is walking back and forth in the room, the receiving device of the sweeping machine and the control system of the mopping machine will synchronously receive the instruction from the sensor through the Internet of Things system platform, so that the sweeping machine and the mopping the machine can change the direction of operation in a timely manner to avoid the collision to the movement of people or pet situation, through the use of intelligent home in the Internet of things technology, making smart home equipment more automated identification, to avoid the man to set and configure the trouble. At the same time, through the Internet of things access technology, but also allows people to stay in the horizon, but also be able to remotely control the home life of all electrical equipment.

Miniaturization Trend. Nowadays, the application of Internet of Things technology in smart home began to make more and more intelligent home products gradually from silly stupid crude gradually to the short and pithy micro-development, this smart home products are gradually due to space saving and easy to use, Simple, professional and other characteristics, more and more by the market's favor. Smart home equipment, small and beautiful style, but also gradually win the world's consumer goodwill, which will be the Internet of things in the application of smart home is another important development trend.

Easy to Operate Trend. There is no doubt that simple and easy to operate home appliances are always easier to get the attention of consumers, and simple and convenient operation can save people a lot of time. Therefore, more and more Internet of Things technology through the computer, mobile phones, digital TV and other terminal equipment to help smart home to achieve easy operation of the function.

Humanization Trend. Market competition will require smart home to focus on different types of consumer groups needs, Internet of Things technology can provide differentiated products, as well as differentiated services to attract different groups of consumer groups, the Internet of things in the application of intelligent home through the people-oriented thinking, will be able to more humane way to win the market.

\section{Conclusion}

With the continuous development of high-speed science and technology in the world, the Internet of Things technology has increasingly shown its important position. The application of Internet of Things technology in smart home has become an irresistible trend in today's era, making smart home more diverse It is a place of life that provides a comfortable and superior service for people's lives.

\section{References}

[1] Yong Zeng, Dong Jing, Song Guangjun, et al. Design of Intelligent Home Wireless Sensor Network Node [J]. Manufacturing Automation, 2013 (3): 193-195.

Design and Implementation of Intelligent Home Control System Based on Internet of Things [J]. Electronic World, 2012 (21) 
[3] Tian Li. Internet of Things in the field of intelligent home applications [J]. Communication and Information Technology, 2014 (2): 74-77. 